\title{
Um Curso Prático de Cinética Química
}

\author{
1. Estudo condutimétrico \\ e espectrofotométrico comparativo da \\ reacção de metanólise do $t$-BuI *
}

\author{
Filomena E.L. Martins ${ }^{a}$ \\ Raquel M.C. Gonçalves ${ }^{\text {a }}$
}

O primeiro objectivo geral do ensino da Cinética Química num curso universitário é o de habilitar os alunos à determinação de velocidades específicas de sistemas reaccionais concretos; o último, de os tornar aptos a propor mecanismos que descrevam eficazmente o comportamento cinético dos sistemas.

Aulas práticas, de conteúdo criteriosamente seleccionado, constituem o suporte para a concretização destes objectivos. Nesse sentido, parece-nos importante familiarizar os alunos com vários tipos de reacçð̄es, processando-se em diferentes meios e cujas evoluçð̋es cinéticas possam ser acompanhadas por diversas vias.

A obtenção de valores de velocidade específica para um sistema reaccional determinado, em igualdade de condições experimentais (concentração, temperatura, pressão, etc.), utilizando mais de um método e de uma técnica, permite, além da satisfação do primeiro objectivo geral, proceder a uma análise comparativa dos. resultados e avaliar da relevância dos métodos e técnicas para o sistema particular em estudo.

Reacçðes escolhidas para este fim devem ter um mecanismo reaccional suficientemente bem esclarecido, os reagentes devem existir comercialmente, a preço módico com um grau de pureza elevado (ou serem facilmente purificáveis) e o apetrechamento laboratorial indispensável à obtenção dos resultados cinéticos deve ser de uso comum.

De acordo com os requisitos enunciados, apresenta-se uma proposta de aula prática que consiste no estudo condutimétrico e espectrofotométrico comparativo da reacção de metanólise do 2-iodo-2-metilpropano (iodeto de butilo terciário: $t$-BuI) (1).

Esta reacção, e de um modo geral qualquer reacção dos halogenetos de alquilo terciário em água e em solventes hidroxílicos de elevada constante dieléctrica, é exemplo típico de comportamento $\mathrm{S}_{\mathrm{N}} 1$ e pode ser descrita por um mecanismo do tipo:

$$
\begin{aligned}
& \left(\mathrm{CH}_{3}\right)_{3} \mathrm{CI} \stackrel{\text { lenta }}{\longrightarrow}\left(\mathrm{CH}_{3}\right)_{3} \mathrm{C}^{+}+\mathrm{I}^{-} \\
& \left(\mathrm{CH}_{3}\right)_{3} \mathrm{C}^{+}+\mathrm{CH}_{3} \mathrm{OH} \stackrel{\text { rápida }}{\longrightarrow}\left(\mathrm{CH}_{3}\right)_{3} \mathrm{OCH}_{3}+\mathrm{H}^{+}
\end{aligned}
$$

para o qual a velocidade é dada por:

$\mathrm{v}=-\frac{\mathrm{d}\left[\left(\mathrm{CH}_{3}\right)_{3} \mathrm{CI}\right]}{\mathrm{dt}}=\mathrm{k}\left[\left(\mathrm{CH}_{3}\right)_{3} \mathrm{CI}\right]=\mathrm{k}[\mathrm{HI}]$

A correspondente velocidade específica, $\mathrm{k}$, pode ser determinada, com facilidade, a partir de medidas de concentração (ou de uma propriedade com ela relacionada) do reagente e/ou do produto.
A implementação desta proposta de aula pressupõe a definição de conteúdos programáticos, de objectivos específicos e de uma distribuição horária conveniente; implica, ainda, a apresentação de uma estratégia, sob a forma de um protocolo orientador para o aluno, e o levantamento dos recursos de material, equipamento e reagentes necessários. Estes aspectos, bem como a aplicação a um caso concreto, serão em seguida enumerados.

\section{CONTEÚdOS PROGRAMÁticos}

- Lei de velocidade integrada para reacçð̄es irreversíveis de 1 . $^{\text {a }}$ ordem.

- Métodos de intervalo de tempo constante para reacções irreversíveis de 1 . $^{\mathrm{a}}$ ordem. (Método de Guggenheim e de Kezdy-Swinbourne) (2).

- Mecanismo das reacções de solvólise dos halogenetos de butilo terciário (1-3).

\section{OBJECTIVOS ESPECÍFICOS}

- Opera as técnicas condutimétrica e espectrofotométrica para fins cinéticos e de identificação.

- Calcula velocidades específicas da metanólise do $t$ -BuI, utilizando a lei de velocidade integrada para reacções irreversíveis de $1^{\text {a }}$ ordem e os métodos de Guggenheim e de Kezdy-Swinbourne. Usa análise de regressão linear.

- Avalia da relevância dos métodos e técnicas utilizados na determinação de velocidades específicas para a reacção em estudo.

\section{DURAÇÃo PREVISTA}

- Introdução teórica: $2 \mathrm{~h}$.

Introdução e revisão de conceitos, metodos e técnicas envolvidas na determinação experimental e no cálculo da velocidade específica. Algumas consideraçðes sobre o mecanismo das reacções de solvólise de halogenetos de alquilo terciário e sobre a aplicação das técnicas condutimétrica e espectrofotométrica à reacção em estudo $(4,5)$.

- Execução experimental

Utilização da técnica condutimétrica: $4 \mathrm{~h}$.

Utilização da técnica espectrofotométrica: $4 \mathrm{~h}$.

- Discussão dos resultados: $2 \mathrm{~h}$.

\footnotetext{
* Este artigo resume parte do relatório da prova de Aptidão Pedagógica de Filomena E.L. Martins, realizado em 88/3/18, na Faculdade de Ciências de Lisboa, ao abrigo do Estatuto da Carreira Docente Universitária.

a CECUL, Faculdade de Ciências de Lisboa, Calçada Bento da Rocha Cabral, 14, 1200 Lisboa.
} 


\section{PROTOCOLO ORIENTADOR}

\section{Título: ESTUDO CONDUTIMÉTRICO E ESPEC- TROFOTOMÉTRICO DA REACÇÃO DE METANÓ- LISE DO $t$-BuI}

2. Objectivos: Determinação da velocidade específica da metanólise do $t$-BuI, por condutimetria e espectrofotometria e por aplicação directa da lei de velocidade integrada para reaç̧̋̃es irreversíveis de $1 .^{\text {a }}$ ordem e métodos de intervalo de tempo constante.

3. Condições experimentais: $[t-\mathrm{BuI}]=0,01 \mathrm{~mol} \mathrm{dm}^{-3}$; solvente $=$ metanol; $\mathrm{T}=40,0{ }^{\circ} \mathrm{C}$.

\section{Realização experimental:}

Parte $I$ - Condutimetria

Coloque o termóstato à temperatura requerida, assegurando que as oscilações de temperatura não sejam superiores a $0,05{ }^{\circ} \mathrm{C}$. Encha um balão de $50 \mathrm{~cm}^{3} \mathrm{com}$ o solvente e coloque-o a termostatizar durante cerca de 15 minutos, juntamente com uma célula de condutividade, previamente coberta com folha de alumínio para se evitar o posterior contacto da solução reaccional com a luz. Adicione ao balão, rapidamente, a quantidade de $t$-BuI necessária para obter a solução na concentração desejada. Inicie a contagem do tempo a meio da adição. Agite vigorosamente e transfira a solução, assim preparada, para a célula de condutividade (evite o contacto com o ar). Rolhe bem a célula.

Aguarde que se estabeleça o equilíbrio térmico (alguns minutos) e inicie as leituras de condutância, em intervalos regulares de $30 \mathrm{~s}$.

Verifique, periodicamente, a temperatura do banho. Siga a reacção até perto do patamar.

Após o termo do ensaio, lave a célula de condutividade, passando-a 3 ou 4 vezes por etanol e, finalmente, pelo solvente utilizado.

Repita o ensaio.

\section{Parte II - Espectrofotometria}

Regule o termóstato do espectrofotómetro para a temperatura requerida.

a) Identificação

Prepare soluçð̃es $0,01 \mathrm{~mol} \mathrm{dm}^{-3}$ de $t$-BuI, KI, $\mathrm{I}_{2}$ e KI e $\mathrm{I}_{2}$ em metanol. Trace os espectros das soluçōes entre 200 e $600 \mathrm{~nm}$. Para isso, transfira, rapidamente, cerca de $2 \mathrm{~cm}^{3}$ de cada uma das soluçðes para a célula de absorção. Tape a célula, cubra a tampa com parafilme e introduza-a no compartimento do espectrofotómetro. Use o solvente como branco.

Identifique o pico característico do $t$-BuI.

b) Reacção

Siga a reacção de metanólise do $t$-BuI por medidas de absorvância ao comprimento de onda a que corresponde o pico de máxima absorção deste con posto, até que os valores se apresentem aproximadamente constantes.

Repita o ensaio depois de lavar a célula várias vezes com etanol, secá-la e passá-la pelo solvente a utilizar. c) Curva de calibração

Verifique que o comprimento de onda do pico característico do $t$-BuI é praticamente independente da temperatura, na gama $\left[0-40^{\circ} \mathrm{C}\right]$.

Prepare $200 \mathrm{~cm}^{3}$ de uma solução $0,01 \mathrm{~mol} \mathrm{dm}^{-3}$ de $t$-BuI em $\mathrm{MeOH}$. Conserve-a em gelo. A partir dela, prepare, em balð̄es de $50 \mathrm{~cm}^{3}$, várias soluçð̃es de acordo com os seguintes factores de diluição: 1:4, 2:3, $1: 1,3: 2,4: 1$, e $1: 10$. Utilize metanol previamente arrefecido.

Determine as absorvâncias correspondentes a cada uma destas soluçðes ao comprimento de onda de identificação.

\section{Análise dos resultados:}

Parte I

1 - Represente graficamente a condutância, $\mathrm{G}_{\mathrm{t}}$, e In $\left|G_{t+\Delta t}-G_{t}\right|$ em função do tempo, t, $G_{t}$ em função de $G_{t+\Delta t}$, depois de escolher um periodo de tempo constante, $\Delta t$, conveniente. Analise, criticamente, estes gráficos.

2 - Estime os valores da velocidade específica, $\mathrm{k}$, e respectivos desvios padrão, $\sigma_{\mathrm{k}}$, aplicando uma regressão linear simples aos pontos dos gráficos correspondentes aos dois métodos de intervalo de tempo constante. Compare os resultados obtidos.

\section{Parte II}

1 - Trace o gráfico de absorvância, A, em função de t e a curva de calibração de $\mathrm{A}$ em função da concentração, c. Analise o tipo de relação existente entre A e c e utilize análise de regressão linear múltipla para estimar os parâmetros ajustáveis à curva, se achar conveniente.

2 - Tranforme os valores de A reaccionais em valores de $\mathrm{c}$ e represente graficamente $1 \mathrm{n} \mathrm{c}$ em função de $\mathrm{t}$, se necessário.

3 - Com base na lei de velocidade integrada para reacções irreversíveis de $1 .^{a}$ ordem, estime $\mathrm{k}$ e $\sigma_{\mathrm{k}}$ para os dois ensaios, aplicando regressão linear simples. Compare os valores obtidos.

\section{Parte III}

1 - Justifique a não exposição ao ar e à luz da solução reaccional.

2 - Apresente razões para a lavagem das células ser feita com etanol e não com água.

3 - Justifique por que a curva de calibração foi feita com as soluçðes a baixa temperatura.

4 - Identifique os vários picos observados nos espectros não reaccionais.

5 - Discuta, criticamente, os valores de $\mathrm{k}$ obtidos pelo método de Guggenheim e de Kezdy-Swinbourne, por um lado, e por condutimetria e espectrofotometria, por outro. Tome em consideração as características de cada método e as condiçð̄es de aplicabilidade de cada técnica.

\section{Bibliografia:}

- K.J. Laidler, "Chemical Kinetics”, 3. " ed., Harper and Row, New York, 1987.

- L. Albuquerque e R. Gonçalves, "Cinética Química", Escolar Editora, Lisboa, 1986.

- J. Robbins, "Ions in Solution", Clarendon Press, Oxford, 1972. - D.A. Skoog and D.M. West, "Analytical Chemistry", Saunders Sunburst Series, 3. ${ }^{a}$ ed., Philadelphia, 1980.

- H.H. Jaffé and M. Orchin, "Theory and Application of Ultraviolet Spectroscopy", John Wiley and Sons, New York, 1970.

- P.R. Bevington, "Data Reduction and Error Analysis for the Physical Sciences", McGraw-Hill, New York, 1966.

\section{RECURSOS}

- Material

. células de condutividade

células de absorção de sílica vítrea transparente 
. balסes, pipetas e pompettes - parafilme e folha de alumínio

- Equipamento

- ponte de condutâncias

- espectrofotómetro de visível e ultra-violeta

- termóstato

- termómetro de décimas

. cronómetro

- Reagentes

. 2-iodo-2-metilpropano ( $t$-BuI)

- metanol (\% água <0,02)

. iodo

- iodeto de potássio

\section{EXEMPLO}

A solvólise do $t$-BuI em metanol, a $40^{\circ} \mathrm{C}$ foi seguida por medidas de condutância. Nas Figuras 1 a 3 estão representadas as variaçð̄es de $G_{t}$ e $\ln \left|G_{t}+\Delta t-G_{t}\right|$ com $t$ e $G_{t}$ com $G_{t+\Delta t}(\Delta t=540 \mathrm{~s})$. Os espectros de visível e ultra-violeta, correspondentes às soluçðes de $t$-BuI, KI, $\mathrm{I}_{2}$ e $\mathrm{KI}$ e $\mathrm{I}_{2}$ em metanol, mostram-se na Figura 4, (a) a (d). A variação da absorvância com o tempo, a curva de calibração de A em função de c e o gráfico de ln c $v s$. $t$, para a metanólise do $t$-BuI, apresentam-se nas Figuras 5 a 7.

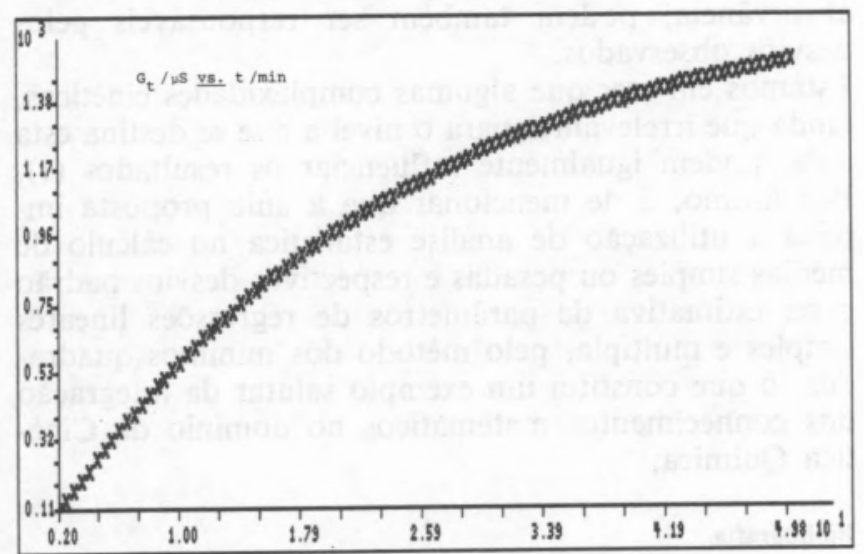

FIGURA 1

Variação de $G_{t}$ com t para a metanólise do t-BuI, a $40{ }^{\circ} \mathrm{C}$

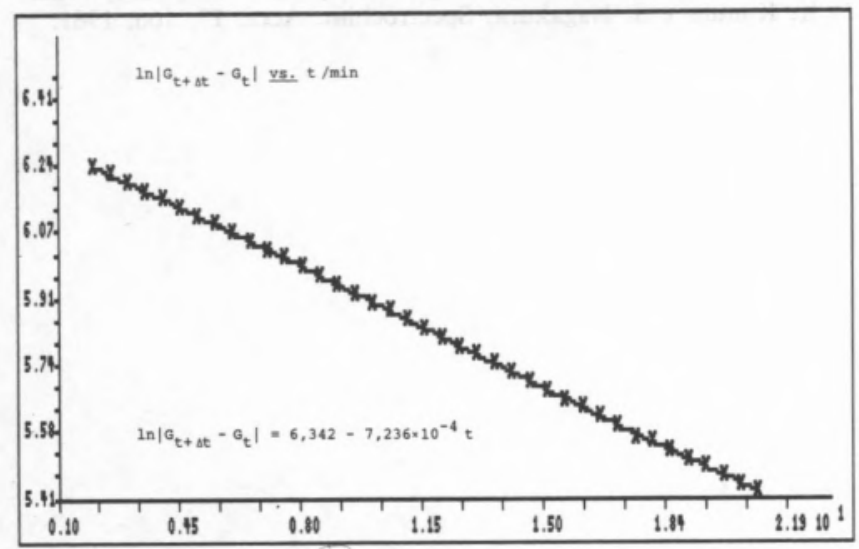

FIGURA 2

Variação de $\ln \left|G_{t+\Delta t}-G_{t}\right|$ com $t$ para a metanólise do t-BuI, a $40{ }^{\circ} \mathrm{C}$ (Método de Guggenheim)

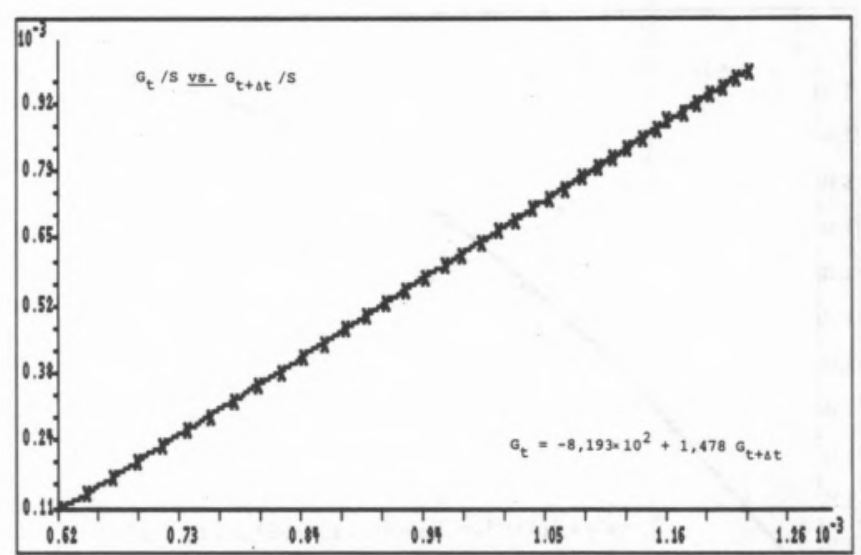

\section{FIGURA 3}

Variação de $G_{t}$ com $G_{t+\Delta t}$ para metanólise do $t$-BuI, a $40{ }^{\circ} \mathrm{C}$ (Método de Kezdy-Swinbourne) (a) $t$-BuI

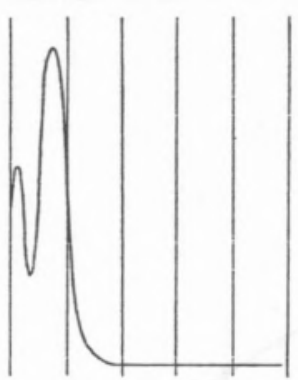

(c) $\mathrm{I}_{2}$

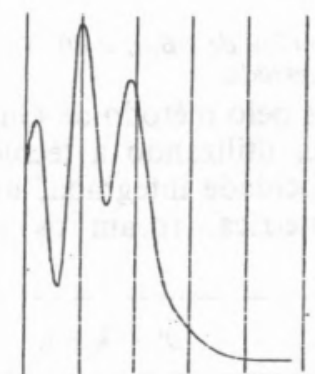

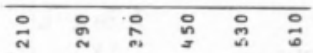

(b) KI

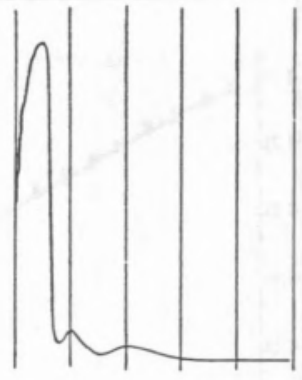

(d) $\mathrm{KI}+\mathrm{I}_{2}$

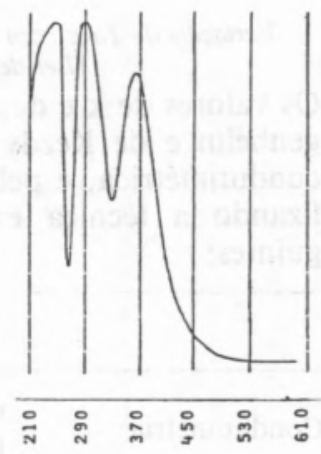

FIGURA 4

Espectros de absorção em metanol

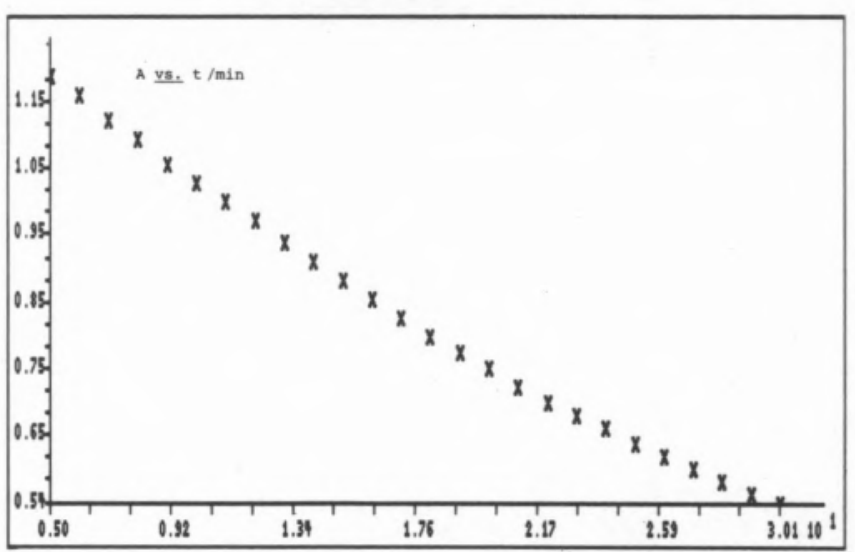

FIGURA 5

Variação de A com t para a metanólise de t-BuI, a $40{ }^{\circ} \mathrm{C}$ 


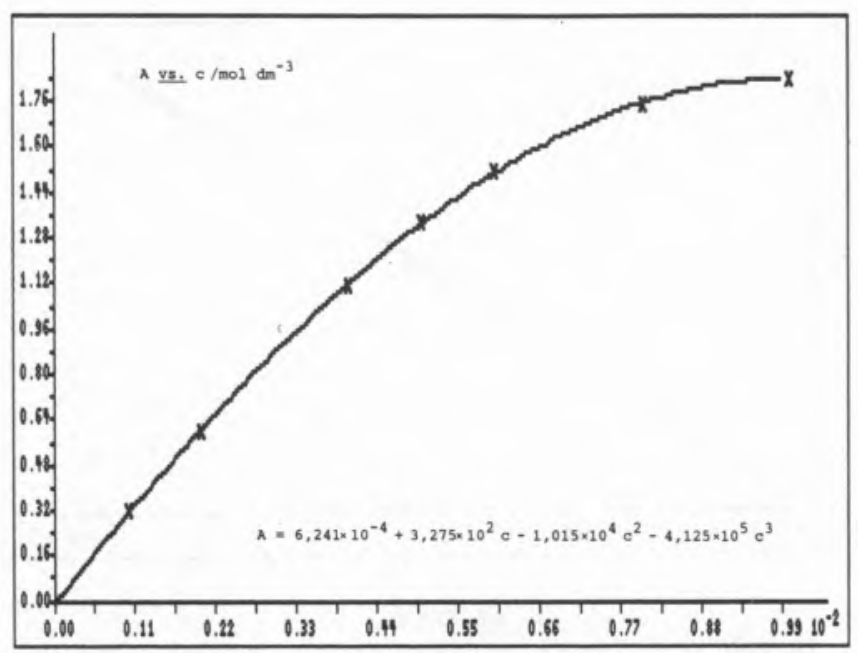

FIGURA 6

Variação de A com c para a metanólise de t-BuI, a $40{ }^{\circ} \mathrm{C}$ (Curva de calibração)

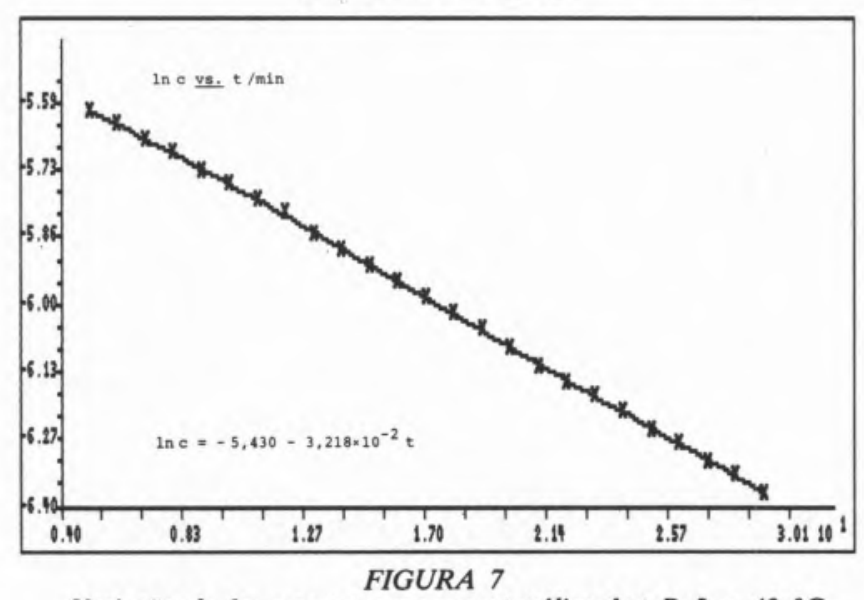

Variação de ln c com t para a metanólise de t-BuI, a $40^{\circ} \mathrm{C}$ (Lei de velocidade integrada)

Os valores de $\mathrm{k}$ e de $\sigma_{\mathrm{k}}$ estimados pelo método de Guggenheim e de Kezdy-Swinbourne, utilizando a técnica condutimétrica, e pela lei de velocidade integrada, utilizando a técnica espectrofotométrica, foram os seguintes:

\begin{tabular}{llr}
\hline & & $10^{4} \times\left(\mathrm{k} \pm \sigma_{\mathrm{k}}\right) / \mathrm{s}^{-1}$ \\
\hline \multirow{2}{*}{ Condutimetria } & Guggenheim & $7,24 \pm 0,02$ \\
Espectrofotometria & Kezdy-Swinbourne & $7,23 \pm 0,02$ \\
& & $5,36 \pm 0,02$ \\
\hline
\end{tabular}

\section{ALGUNS COMENTÁRIOS}

O estudo prático proposto permite, de acordo com as hipóteses metodológicas implícitas, obter a mesma informação por vias independentes: a velocidade específica reaccional, quer seguindo a evolução do reagente, $t$-BuI, por espectrofotometria e por utilização da lei de velocidade integrada, após calibração se necessária, quer seguindo o comportamento do produto da reacção, HI, por condutimetria e por utilização de dois métodos de intervalo de tempo constante. Uma terceira via é ainda sugerível: a determinação de $\mathrm{k}$ recorrendo a medidas titulimétricas do ácido iodídrico formado. Discrepâncias nos valores de $\mathrm{k}$ obtidos pelo método de Guggenheim e de Kezdy-Swinbourne devem ser muito pequenas, uma vez que ambos se baseiam no mesmo conjunto de pressupostos; é apenas de referir que o segundo método é mais expedito e confere maior peso aos pontos experimentais obtidos na primeira parte da reaç̧ão. Por outro lado, diferenças com significado estatístico entre os valores de velocidade especifica determinados por via condutimétrica e por via espectrofotométrica são admissíveis, uma vez que foi aceite sem confirmação, por exemplo, a linearidade condutância da solução - concentração de HI; além disso, outros factores tais como o controlo da temperatura, com frequência deficiente em termóstatos de circulação, e que afectariam, neste caso, os valores de absorvância, podem também ser responsáveis pelos desvios observados.

Estamos em crer que algumas complexidades cinéticas, ainda que irrelevantes para o nível a que se destina esta aula, podem igualmente influenciar os resultados (1). Por último, é de mencionar que a aula proposta implica a utilização de análise estatística no cálculo de médias simples ou pesadas e respectivos desvios padrão e na estimativa de parâmetros de regressð̃es lineares simples e múltipla, pelo método dos mínimos quadrados, o que constitui um exemplo salutar da integração dos conhecimentos matemáticos no domínio da Cinética Química.

\section{Bibliografia}

1. F.E.L. Martins, relatório da prova de Aptidão Pedagógica, Lisboa, 1988.

2. L. Albuquerque e R. Gonçalves, "Cinética Química", Escolar Editora, Lisboa, 1986.

3. M.J. Blandamer, J.M.W. Scott e R.E. Robertson, Prog. Phys. Org. Chem., 15, 149, 1985.

4. J. Biordi e E.A. Moelwyn-Hughes, J. Chem. Soc., 4291, 1962.

5. K. Kimura e S. Nagakura, Spectrochim. Acta, 17, 166, 1961. 